DOI: https://doi.org/10.25146/2587-7844-2020-11-3-49

\title{
УДК 821.161.1
}

\section{ЛИТЕРАТУРНЫЕ ПОРТРЕТЫ \\ ПИСАТЕЛЕЙ-«ДЕРЕВЕНЩИКОВ» \\ В КРИТИКЕ ЖУРНАЛА „СИБИРСКИЕ ОГНИ»}

\section{Е.А. Андреева (Красноярск, Россия)}

\section{Аннотация}

Проза писателей-«деревенщиков» занимает особое место в литературно-критическом дискурсе «Сибирских огней». Большую часть статей, посвященных В. Астафьеву, В. Шукшину, В. Абрамову, занимают литературные портреты, в которых представлен взгляд критика на жизненный путь и личность рассматриваемого автора. Литературно-критический дискурс о современной традиционалистской прозе становился объектом внимания Е. Добренко, И. Чеканниковой, Л. Соколовой, однако вопрос о ее рецепции в региональных изданиях остается неизученным. Цель статьи - проанализировать представленные на страницах «Сибирских огней» литературные портреты, выявить устойчивый комплекс мотивов или элементов образа, встроенных в сюжет о писателе. Материалом для исследования послужили статьи, опубликованные в период с 1986 по 2010-е годы. Методологическую базу составляют работы Ю. Говорухиной, М. Берга, представляющие литературно-критический дискурс как властный, в котором одной из ключевых задач критика является убеждение читателя в истинности своих суждений и формирование определенной картины мира в сознании адресата.

В ходе исследования были сделаны следующие выводы. В творчестве писателей«деревенщиков» реализуются основные ценностные установки дискурса «Сибирских огней»: сохранение национальных и культурных традиций, провозглашение нравственных принципов, интерес к человеку «естественному», сакрализация образа Сибири, провинции. Главной задачей критиков журнала является формирование положительной установки на восприятие писателей-традиционалистов второй половины XX века. Основу литературных портретов составляют, как правило, воспоминания современников или самого критика. В описании жизненного пути или образа писателя-«деревенщика» можно выделить устойчивые доминирующие элементы. Это мотив преодоления жизненных трудностей, предначертанности писательского пути, неразрывной связи с малой родиной; ключевыми элементами образа становятся стойкость духа, трудолюбие, героизм, избранность, исключительность, близость народу. Писатели-«деревенщики» зачастую предстают как спасители в ситуации глобального культурного кризиса, в то время как их прозе отводится функция хранителя национальных мифов и сакрального пространства русской деревни.

Ключевые слова: литературно-критический дискурс, «толстый» журнал, «Сибирские огни», современная традиционалистская проза, «деревенская проза», писатели«деревенщики», Сибирь, В. Астафьев, В. Шукиин, Ф. Абрамов.

остановка проблемьл. «Сибирские огни» - одно из старейших региональных изданий, с 1920-х годов представляющих литературу и публицистику Сибири. На страницах журнала были напечатаны знаковые произведения писателей-традиционалистов, среди которых романы В. Шукшина «Любавины», 
«Я пришел дать вам волю», повести В. Астафьева «Кража», В. Распутина «Деньги для Марии», первая часть эпопеи В. Шишкова «Угрюм-река», романы А. Иванова «Вечный зов», «Повитель», роман А. Черкасова «Хмель». Критики отводят важную роль «Сибирским огням» в становлении таких авторов, как В. Астафьев, В. Шукшин, В. Распутин, С. Залыгин, П. Проскурин: «Да, именно наш журнал помог им сделать первые шаги в литературе, встать на ноги, и мы гордимся этим», - отмечает А. Горшенин (Горшенин, 1990, с. 126).

Проза «деревенщиков» занимает особое место в литературно-критическом пространстве журнала. Это обусловливается тем, что в произведениях В. Астафьева, В. Распутина образ Сибири романтизируется, рассматривается в рамках утопического мифа, где русский Север осознается как сакральное, национальное пространство, «избранная земля, дарующая человеку не только земной рай, но и прозрение истины» [Ковтун, 2009, с. 71]. Кроме того, для В. Астафьева, В. Распутина, В. Шукшина Сибирь является малой родиной, их произведения открывают читателю красоту ее природы, а также жизненный уклад и характер сибиряков ${ }^{1}$. Со многими из писателей критики имели личное знакомство и даже поддерживали дружескую связь. Этим объясняется тот факт, что большую часть критических статей о «деревенщиках», опубликованных в журнале «Сибирские огни», занимают именно литературные портреты. Анализу различных литературных портретов писателей-традиционалистов второй половины XX века посвящена данная статья. Материалом для исследования послужили статьи, опубликованные в период с 1986 по 2010-е годы.

В.Н. Крылов выделяет три компонента творческого пути художника: биография, созданный им мир, реальный мир (контекст эпохи и общества) [Крылов, 2016 , с. 74]. В зависимости от преобладания того или иного компонента выделяются две разновидности литературного портрета: критико-биографический очерк и портрет-предисловие, который «настраивает» читателя на определенное восприятие книги. В. Барахов предлагает рассматривать литературный портрет как жанр мемуарно-автобиографической литературы (основывается на воспоминаниях автора) или как документально-биографическое повествование о какомлибо деятеле с использованием документов (писем, свидетельств современников и т.д.) [Барахов, 1982]. Общим местом этой жанровой разновидности критики является ее автобиографизм. Критик изображает писателя сквозь призму своего индивидуального восприятия, обращаясь к воспоминаниям отдельных событий, в которых переплетаются их судьбы. Фигура автора, субъекта здесь имеет структурообразующую роль, поскольку он оценивает идеи, поступки своего «героя», отмечает его роль в собственной жизни. Как замечает В.С. Барахов, автор литературного портрета «извлекает из своего личного общения с характеризуемым человеком главное, определяющее и фокусирует его в завершенном образе»

\footnotetext{
Стоит сказать, что такой факт биографии писателя, как рождение в Сибири, наделяется особым смыслом и в литературно-критическом дискурсе «патриотов» (журналы «Наш современник», «Молодая гвардия», «Москва»), обнаруживающим точки соприкосновения с критическим пространством «Сибирских огней» [Андреева, 2018].
} 
[Барахов, 1985, с. 55]. Описание биографии писателя с остановкой на значимых для критика фактах, создание определенного образа представляется актом творчества, в результате которого рождается, по словам исследователя, «повесть человека о человеке» [Там же].

В литературном портрете за писателем усматривается прежде всего личность, человек, несущий определенные идеи, с которыми критик может соглашаться или не соглашаться. Сосредоточивая внимание на жизненном пути и взглядах описываемого автора, критик, по сути, уходит от своей главной задачи - работа с художественным текстом, его интерпретация и оценка. Однако такой экскурс в биографию и эпоху открывает читателю дополнительные возможности для более глубокого понимания личности писателя и исторического контекста. Как отмечает О.А. Айкашева, «литературный портрет способен выступать не только в качестве определенной формы критической рефлексии, но и как научное и историко-документальное исследование жизни какой-либо выдающейся личности» [Айкашева, 2012].

Результаты исследования. Критические статьи «Сибирских огней» зачастую представлены в форме записи непосредственных впечатлений от встреч с писателем, подкрепленных напрямую выраженным отношением к изображаемому. Писатель выступает здесь как своего рода «персонаж», «герой», наделенный определенными качествами. В литературно-критическом пространстве журнала «деревенская проза» маркируется как «своя», поскольку отражает основные его ценностные ориентиры (сохранение национальных и культурных традиций, провозглашение нравственных принципов, интерес к человеку «естественному») и представляет темы деревни, провинции, Сибири, составляющие «символический капитал» регионального издания. Поэтому главной задачей критика становится формирование положительной установки на восприятие писателя.

При анализе литературных портретов, посвященных В. Астафьеву, можно обнаружить устойчивый комплекс мотивов или элементов образа, встроенных в сюжеты о писателе. Первое, на что обращают внимание читателя критики, - обаяние, открытость, хорошее чувство юмора В. Астафьева, его умение быть в центре внимания. Так, И. Подсвиров замечает, что Астафьев был «человечен, общителен и остроумен, привлекал к себе многих душевной распахнутостью, обаянием, заразительными рассказами и смехом» (Подсвиров, 2012). Его обаяние объясняется умением держать внимание публики словом: «Он был неисчерпаемой кладезью баек и народной мудрости» (Там же). А. Астраханцев упоминает его способность выстраивать образную, логичную, аргументированную речь (Астраханцев, 2004). С. Ермолаева, вспоминающая свою встречу с Астафьевым, также замечает, что его речь «невозможно передать достоверно, настолько она проста и образна» (Ермолаева, 2006). За В. Астафьевым закрепляется устойчивое представление о нем как о мастере слова - как в жизни, так и в творчестве. Критики выдвигают идею о его исключительном писательском таланте: «Так написать мог только Астафьев» (Подсвиров, 2012); «...никто из современных писателей так полно и глубоко, как Астафьев, не преломил в своей натуре и своем твор- 
честве русскую ментальность, так органично не соединил крайности, которыми знаменита русская душа» (Шленская, 2006); «Просто восхищает, с каким мастерством он может описывать, например, не природу с точки зрения человека - а человека с точки зрения самой природы» (Астраханцев, 2004). Доминантой образа писателя становится подлинность его писательского таланта, проявленного и в способности привлекать внимание словом, а также наличие редкого дара, позволяющего по-особому раскрывать в своих произведениях темы русского национального характера и взаимоотношений человека и природы.

При этом критики указывают на некоторое противоречие характера Виктора Петровича: при всей своей душевности и открытости он был человеком одиноким. Г. Шленская замечает, что у писателя настоящих друзей было немного (Шленская, 2006), а И. Подсвиров называет его «художником-одиночкой», который чувствовал себя «как рыба в воде в домашней атмосфере, в соседстве с природой» (Подсвиров, 2012). А. Астраханцев объясняет его обособленность тяжелым характером, упрямством и «нетерпимостью к чужим мнениям», о его нетерпимости, резкости в суждениях пишет и Э. Русаков. Подчеркивается еще одна важная черта - независимость и своеволие художника, заключающиеся в умении противостоять общественному мнению. Мотив одиночества, реализуемый в «сюжетах» о В. Астафьеве, придает образу мастера ореол избранности, становится показателем его внутренней силы и стойкости.

Центральное место в изображении В. Астафьева критиками «Сибирских огней» занимает образ правдолюбца, писателя, разрушающего мифы и иллюзии, обличающего ложь. Г. Шленская вспоминает, как на одной из встреч с читателямиземляками В. Астафьеву задали вопрос о военной прозе. Он считал, что «в произведениях современных авторов о войне нет полнокровной правды, ибо война увидена в них глазами либо офицера, либо журналиста, и никогда - из окопов глазами рядового ее участника» (Шленская, 2006). Именно В. Астафьеву, рядовому «из окопов», была явлена ужасающая картина войны, которую впоследствии он передал в романе «Прокляты и убиты», подвергавшемся обвинениям в неправдоподобии. Его честность и прямота становятся отличительной чертой: Э. Русаков называет его «неудобным классиком» и вспоминает, как в застойные годы он «не скрывал своего отношения к большевикам» (Русаков, 2004).

По наблюдению критиков, реалистичность мира, изображаемого писателем, свойственна не только его произведениям о войне. И. Подсвиров писал, что творчество В. Астафьева интересно именно тем, что в нем открывается «правда жизни». Э. Русаков проводит черту между живой и естественной прозой В. Астафьева и современными авторами - Т. Толстой, Б. Акуниным, В. Пелевиным, чьи книги «не трогают душу и сердце», в то время как произведения Виктора Петровича «обжигают прямой речью» (Русаков, 2004).

Еще один повторяющийся элемент статей, посвященных В. Астафьеву, мотив тяжелого жизненного пути писателя, благодаря которому он смог пережить и затем передать в произведениях свой несоизмеримый опыт. В. Яранцев представляет 
В. Астафьева как человека, пережившего войну, подвергавшегося искушению «премиями и орденами», но сумевшего сохранить себя в тяжелое перестроечное и постперестроечное время (Яранцев, 2014). Критики обращают внимание читателя на то, что тяжелые испытания, выпавшие на долю В. Астафьева, не сломили писателя, а, наоборот, закалили его, сделали сильнее. Этим объясняет, с одной стороны, жесткость его характера, с другой - стремление научить, защитить, спасти, отразившееся в «жгучей боли за русского человека» (Русаков, 2004). «Сюжет» о писателе наделен героическим мотивом: в нем показана его духовная стойкость, способность сохранить себя, свои нравственные и моральные принципы, не сломаться под действием исключительно тяжелых жизненных обстоятельств.

На страницах «Сибирских огней» можно встретить критико-биографические очерки, содержащие воспоминания не только самого критика, но и близких писателю людей (или знакомых с ним). В них, как правило, представлен какой-либо отрезок жизни писателя с хронологическим изложением событий, которые проиллюстрированы воспоминаниями современников. В данном случае критик также реализует установку на формирование положительного образа писателя. Показательна статья В. Гришаева, посвященная истокам творческого пути В. Шукшина. Разворачивая биографический пласт детства Василия Макаровича, критик отмечает его раннюю тягу к литературе. Он приводит воспоминания его однокашников: «Любил литературу. Много читал. Сочинения хорошо писал» (Гришаев, с. 157). Так критик вводит мотив предначертанности пути своего «героя», чей талант и любовь к писательскому делу проявились еще в детстве. Важной деталью является упоминаемый критиком «блокнот с распятием», в котором В. Шукшин писал свои первые сочинения. Он становится знаком избранности писателя: «Чуть выдастся свободный час - вынимает свой блокнот с распятием и что-то строчит» (Там же). Такой факт биографии, как учеба Василия Макаровича в Бийском автомобильном техникуме и последующее исключение из него, наделяется особым смыслом в контексте размышлений о его даровании: «Здесь он начал осознавать свое призвание и сделал первые шаги к заветной цели» (Там же, c. 159). Обозначая техникум как отправную точку его писательского пути, критик отмечает, что «путь предстоял ему далекий и трудный» (Там же).

Мотив жизненных трудностей, испытаний является одним из главных в формировании положительного образа писателя: критик упоминает «нелегкие годы скитаний» В. Шукшина после отчисления из техникума и замечает, что «жизнь его не баловала» (Там же). Вместе с этим становление Василия Макаровича как писателя представляется неизбежным: это призвание, вслед за которым он шел, преодолевая все преграды. Его писательский успех не случайность, а результат многолетних усилий: «Писал Василий много и упорно» (Там же, с. 158).

Также в образе писателя доминирующими элементами становятся смелость, сила духа и стойкость характера. Критик акцентирует внимание на том, что после отчисления из техникума В. Шукшин «с безрассудной решимостью бросился, словно в омут, в огромную неведомую жизнь, без гроша в кармане, с одной 
надеждой на свои силы да на юношеские, весьма и весьма незрелые сочинения» (Там же, с. 159). Достижения писателя стали возможны благодаря силе его характера: «Ничего не побоялся. Это характер. Не имей Шукшин такого характера немного он добился бы в жизни» (Там же). Жизнестроительная модель Василия Макаровича представляется как ориентир для читателя, где готовность писателя преодолевать трудности и вера в собственные силы - главные ценности.

Кроме этого, критик подчеркивает, что односельчанам он запомнился своей добротой и отзывчивостью, а также заботой о своей малой родине и ее жителях. Так, однокашник Шукшина вспоминает: «Как встретимся, у него первый вопрос: „Что нужно селу?” (Там же, с. 158). Критик показывает, что писатель сохранил связь с родной землей и после получения признания его писательского таланта. В качестве доказательства В. Гришаев приводит воспоминания Д. Фалеевой, заведующей библиотекой в Сростках, которая знала Шукшина с детства. Она рассказывает о его творческих встречах с односельчанами, произошедших в 1967 и 1870 годах: «Таким он мне запомнился в тот вечер - простым, деревенским. Ничего, казалось, не взял от того круга людей, в котором вращался» (Там же, с. 169). Тот факт, что В. Шукшин сохранил в себе деревенскую простоту и остался близок народу, несмотря на продолжительную жизнь в Москве, оказывается особенно значимым для критика. В рамках литературно-критического дискурса «Сибирских огней» отчетливо прослеживается оппозиция «столица - провинция», где «провинция» маркируется как место сосредоточения и сохранения национальной культуры, традиций и нравственности ${ }^{2}$. Близость В. Шукшина народу и деревенской жизни подчеркивается во многих статьях о нем. Так, Н. Веселова замечает: «Он хорошо запомнил образ жизни своих земляков. И именно им доверял потом все, что встречал в жизни» (Веселова, 1989, с. 165). Именно там, по словам критика, он находил «ясность, простоту, целесообразность и добрые, естественные, правдивые отношения между людьми» (Там же). А. Родионов, подчеркивая неразрывную связь писателя с родной землей и людьми, называет его «босяк всенародный» [Родионов, 2004]. Г. Ульянова отмечает, что в его размышлениях о России звучала «молитва о родной земле и людях, на ней, этой земле, живущих» (Ульянова, 2010).

В пространстве «Сибирских огней» нередко подчеркивается близость писателя и его любимого героя - Степана Разина. Д. Марьин замечает: «Образ Степана Разина, безусловно, является сквозным не только для творчества, но и для жизни В.М. Шукшина» (Марьин, 2010). Критик рассказывает читателю, с каким трудолюбием собирались материалы о С. Разине: писатель сотрудничал с музейными работниками, изучал исторический материал, консультировался с историком А. Зиминым (Там же). Ключевые элементы этого образа, ставшие его символом, - свобода и воля. Именно такие ассоциации рождаются у А. Родионова при рассмотрении монумента в Сростках: «В руках Шукшина не только покой, но и

\footnotetext{
2 Отметим, что в творчестве самого Шукшина проблема «город» - «деревня», «центр» - «провинция» решается гораздо сложнее и многоаспектнее, сельские люди не идеализируются, автор не высказывает прямых суждений о своих героях и ситуациях, но демонстрирует их сложность [Ковтун, 2012].
} 
воля» (Родионов, 2004). Также критик замечает, как В. Клыков, автор памятника на горе Пикет, сумел объединить в своем творении народную суть писателя «с покоем, волей и пространством» (Там же). Кроме этого, критик представляет В. Шукшина как посредника между человеком и Богом, ссылаясь на этимологию его имени: «Шукша - по мнению Черемис, есть такое божество, которое неотлучно пребывает между людьми. Он примечает действия каждого человека, записывает его пороки и добродетели и тотчас относит оные Богу, живущему на небесах» (Там же). Божественной природой дарования В. Шукшина А. Родионов объясняет его размышления о пороках человечества, о судьбе России, выраженные в вопросе «Что с нами происходит?».

Критику важно показать величие и масштаб личности писателя, чтобы сформировать положительную установку на восприятие его произведений, отражающих ценностные ориентиры журнала. Один из способов привлечения внимания читателя к произведениям автора - определение его как защитника, спасителя, героя. Подобный прием встречается в статье 3. Естамоновой, посвященной Ф. Абрамову, в которой писатель связывается с образом «заступника». В представлении критика он боец за «за суровую правду о русской деревне, которую замалчивали те партократы, которые сегодня перекрасились в либеральных управленцев-временщиков, вобравших в себя все пороки советской системы и ничего от ее великих достоинств» (Естамонова, 2005). Вслед за писателем, 3. Естамонова обеспокоена исчезновением деревень, которые мыслятся неотъемлемой частью России, ее национального духа. Ф. Абрамов изображается как спаситель в ситуации глобального культурного кризиса: размышление о силе его прозы перекликаются с описанием устрашающих современных реалий, ставших символом «духовной нищеты» и признаком грядущей катастрофы.

Отметим, что здесь появляется характерный для патриотического дискурса образ врага-либерала: им выступают писатели, которые «очернили» и «извратили» правду о русской деревне, критики, поддерживающие этих писателей, а также либерально настроенный «Новый мир», отказавшийся печатать заметки Ф. Абрамова о США. Стремление Федора Александровича поспособствовать духовному возрождению России проявлено в незавершенном романе «Чистая книга». Критик замечает: «Федор Абрамов поднимался все выше над пространствами России, глубже проникал в лабиринты времен, прислушивался к голосам поколений ушедших и нынешних, искал перекрестки истории, философских и религиозных учений, и все это затем, чтобы по мере возможности заглянуть вперед, прозреть будущее России» (Там же).

Заключение. Смешение объективного (перечисление фактов биографии) и субъективного (оценка, выражение собственного отношения к изображаемым событиям) определяет идейно-художественную специфику жанра литературного портрета. Критики «Сибирских огней» через собственную оценку изображаемых фактов формируют у читателя установку на положительное восприятие личности и творчества писателей-традиционалистов второй половины ХХ века. Во всем 
многообразии дискурса о «деревенщиках» можно выделить доминирующие мотивы в их жизнеописании или элементы образа, которые повторяются в различных статьях. Это мотив преодоления жизненных трудностей, предначертанности писательского пути, неразрывной связи с малой родиной; ключевыми элементами образа становятся стойкость духа, трудолюбие, героизм, избранность, исключительность, близость народу. На основании проведенного анализа можно сделать вывод, произведения современных писателей-традиционалистов представляются неотъемлемой частью литературного поля «Сибирских огней», а идеология традиционализма оказывается особенно близкой критикам-консерваторам, отстаивающим национальную самобытность и традиции.

\section{Список источников}

1. Астраханцев А. Об Астафьеве В.П., человеке и писателе // Сибирские огни. 2004. № 10. URL: http://www.sibogni.ru/content/o-vp-astafeve-cheloveke-i-pisatele (дата обращения: 07.09.2020).

2. Веселова Н. Душа болит... // Сибирские огни. 1989. № 7. С. 160-170.

3. Горшенин А. Издержки «беглого взгляда» // Сибирские огни. 1990. № 4. С. 124-133.

4. Гришаев В.В. Шукшин. Материалы к биографии // Сибирские огни. 1986. № 5. С. 155-170.

5. Ермолаева С. «...И Астафьева светлый лик» // Сибирские огни. 2006. № 9. URL: http:// www.sibogni.ru/content/i-astafeva-svetlyy-lik (дата обращения: 07.09.2020).

6. Естамонова 3. Заступник // Сибирские огни. № 12. 2005. URL: http://www.sibogni.ru/ content/zastupnik (дата обращения: 07.09.2020).

7. Марьин Д. «Зная вас как активного разинца» // Сибирские огни. 2010. № 2. URL: http:// www.sibogni.ru/content/znaya-vas-kak-aktivnogo-razinca (дата обращения: 07.09.2020).

8. Подсвиров И. Война и мир В. Астафьева // Сибирские огни. 2012. № 6. URL: http://www. sibogni.ru/content/voyna-i-mir-viktora-astafeva (дата обращения: 07.09.2020).

9. Родионов А. «Но есть покой и воля...» // Сибирские огни. 2004. № 9. URL: http://www. sibogni.ru/content/no-est-pokoy-i-volya (дата обращения: 07.09.2020).

10. Русаков Э. Осень патриарха // Сибирские огни. 2004. № 5. URL: http://www.sibogni.ru/ content/osen-patriarha (дата обращения: 07.09.2020).

11. Ульянова Г. «У меня сейчас очень сложные дела...» // Сибирские огни. 2010. № 2. URL: http:// www.sibogni.ru/content/u-menya-seychas-ochen-slozhnye-dela (дата обращения: 07.09.2020).

12. Шленская Г. Взаболь // Сибирские огни. 2006. № 2. URL: http://www.sibogni.ru/content/ vzabol (дата обращения: 07.09.2020).

13. Яранцев В. Праздник, рожденный буднями. В. Астафьев в 1986 году // Сибирские огни. 2014. № 5. URL: http://www.sibogni.ru/content/prazdnik-rozhdennyy-budnyami-astafev-v1986-godu (дата обращения: 07.09.2020).

\section{Библиографический список}

1. Айкашева О.А. Жанровое своеобразие литературного портрета конца XIX - первой половины ХХ века: дис. ... канд. филол. наук. Улан-Удэ, 2012. 163 с.

2. Андреева Е.А. Интерпретационные стратегии литературной критики «патриотов» 2000-х // Сибирский филологический форум. 2018. № 4. С. 19-30.

3. Барахов В.С. Искусство литературного портрета: к постановке проблемы // Литература и живопись. Л.: Наука, 1982. С. 147-168.

4. Барахов В.С. Литературный портрет (истоки, поэтика, жанр). Л.: Наука, 1985. 312 с. 
5. Ковтун Н.В. Образ городской цивилизации в поздних рассказах В.М. Шукшина: миметический и семантический аспекты // Вестник Томского государственного университета. 2012. № 1 (17). С. 74-94.

6. Ковтун Н.В. Природа и религия как основа жизненного уклада в повести В. Астафьева «Стародуб» // Вестник ТГУ. Филология. 2009. № 1 (5). С. 71-83.

7. Крылов В.Н. Русская литературная критика. Проблемы теории, истории и методики изучения. М.: ФЛИНТА, 2016. 239 с.

\section{Сведения об авторе}

Андреева Елена Александровна - аспирант кафедры мировой литературы и методики ее преподавания, Красноярский государственный педагогический университет им. В.П. Астафьева; е-mail: andreeva.elena.krsk@gmail.com 


\title{
LITERARY PORTRAITS OF VILLAGE PROSE WRITERS IN THE CRITICISM OF THE MAGAZINE SIBIRSKIYE OGNI
}

\section{E.A. Andreeva (Krasnoyarsk)}

\begin{abstract}
The prose of the "village prose" writers occupies a special place in the literary and critical discourse of the Sibirskiye Ogni. Most of the articles devoted to V. Astafiev, V. Shukshin, V. Abramov are literary portraits, which present the critic's view of the life and personality of the author in question. The literary and critical discourse on contemporary traditionalist prose became the object of attention by E. Dobrenko, I. Chekannikova, L. Sokolova, but the question of its reception in "thick" regional publications remains unexplored.

The purpose of this article is to analyze the literary portraits presented on the pages of the Sibirskiye Ogni, to reveal a stable complex of motives or image elements embedded in the plot about the writer. The material included articles published in the period from 1986 to 2010. The methodological base is formed by the works of Yu. Govorukhina, M. Berg, representing literary and critical discourse as imperious, in which one of the key tasks of the critic is to convince the reader of the truth of his judgments and to form a certain picture of the world in the addressee.

Research results. The main values of the Sibirskiye Ogni discourse are realized in the works of the "village prose" writers: preservation of national and cultural traditions, proclamation of moral principles, interest in the "natural" man, the sacralization of the image of Siberia and the province. The main task of the magazine's critics is to form a positive attitude towards the perception of traditionalist writers of the second half of the 20th century. The basis of literary portraits, as a rule, are the memoirs of contemporaries or the critic himself, as well as letters. In the description of the life path or image of the "village prose" writer, stable dominant elements can be distinguished. This is the motive for overcoming life's difficulties, the predestination of the writer's path, the inextricable connection with the small homeland; the key elements of the image are fortitude, heroism, hard work, exclusivity, and closeness to the people. Village writers often appear as saviors in a situation of global cultural crisis, while their prose is assigned the function of the keeper of national myths and the sacred space of the Russian countryside.
\end{abstract}

Keywords: literary and critical discourse, "thick" magazine, "Sibirskiye Ogni", modern traditionalist prose, "village prose", "village prose” writers, Siberia, V. Astafiev, V. Shukshin, F. Abramov.

\section{Spisok istochnikov}

1. Astrahancev A. Ob Astaf'eve V.P., cheloveke i pisatele [About Astafiev V.P., man and writer] // Sibirskie ogni. 2004. No 10. URL: http://www.sibogni.ru/content/o-vp-astafeve-cheloveke-ipisatele (data obrashcheniya: 07.09.2020).

2. Veselova N. Dusha bolit... [Soul hurts...] // Sibirskie ogni. 1989. No. 7. S. 160-170.

3. Gorshenin A. Izderzhki ,beglogo vzglyada” [Costs of a „cursory glance”] // Sibirskie ogni. 1990. No. 4. S. 124-133.

4. Grishaev V.V. Shukshin. Materialy k biografii [Materials for the biography] // Sibirskie ogni. 1986. No. 5. S. 155-170.

5. Ermolaeva S. „...I Astaf'eva svetlyj lik” [,„... And Astafieva's bright face”] // Sibirskie ogni. 2006. No 9. URL: http://www.sibogni.ru/content/i-astafeva-svetlyy-lik (data obrashcheniya: 07.09.2020). 
6. Estamonova Z. Zastupnik [Intercessor] // Sibirskie ogni. No. 12. 2005. URL: http://www.sibogni.ru/content/zastupnik (data obrashcheniya: 07.09.2020).

7. Mar'in D. „Znaya vas kak aktivnogo razinca” [„Knowing you as an active ranger”] // Sibirskie ogni. 2010. No. 2. URL: http://www.sibogni.ru/content/znaya-vas-kak-aktivnogo-razinca (data obrashcheniya: 07.09.2020).

8. Podsvirov I. Vojna i mir V. Astaf'eva [War and Peace V. Astafiev] // Sibirskie ogni. 2012. No. 6. URL: http://www.sibogni.ru/content/voyna-i-mir-viktora-astafeva (data obrashcheniya: 07.09.2020).

9. Rodionov A. „No est' pokoj i volya...” [„But there is peace and will...”] // Sibirskie ogni. 2004. No. 9. URL: http://www.sibogni.ru/content/no-est-pokoy-i-volya (data obrashcheniya: 07.09.2020).

10. Rusakov E. Osen' patriarha [Autumn of the Patriarch] // Sibirskie ogni. 2004. No. 5. URL: http:// www.sibogni.ru/content/osen-patriarha (data obrashcheniya: 07.09.2020).

11. Ul'yanova G. „U menya sejchas ochen' slozhnye dela...” ["I have very complicated business now...”] // Sibirskie ogni, 2010. No 2. URL: http://www.sibogni.ru/content/u-menya-seychasochen-slozhnye-dela (data obrashcheniya: 07.09.2020).

12. Shlenskaya G. Vzabol' [Zabol] // Sibirskie ogni. 2006. No. 2. URL: http://www.sibogni.ru/content/vzabol (data obrashcheniya: 07.09.2020).

13. Yarancev V. Prazdnik, rozhdennyj budnyami. V. Astaf'ev v 1986 godu [A holiday born of everyday life] // Sibirskie ogni. 2014. No. 5. URL: http://www.sibogni.ru/content/prazdnik-rozhdennyy-budnyami-astafev-v-1986-godu (data obrashcheniya: 07.09.2020).

\section{References}

1. Ajkasheva O.A. Zhanrovoe svoeobrazie literaturnogo portreta konca XIX - pervoj poloviny XX veka [Genre originality of a literary portrait of the late XIX - first half of the XX century]: dis. ... kand. filol. nauk. Ulan-Ude, 2012. 163 s.

2. Andreeva E.A. Interpretacionnye strategii literaturnoj kritiki ,patriotov” 2000-h [Interpretive strategies of literary criticism of "patriots" of the 2000s] // Cibirskij filologicheskij forum. 2018. No. 4. S. 19-30.

3. Barahov V.S. Iskusstvo literaturnogo portreta: k postanovke problemy [The art of literary portrait: to the formulation of the problem] // Literatura i zhivopis'. L.: Nauka, 1982. S. 147-168.

4. Barahov V.S. Literaturnyj portret (istoki, poetika, zhanr) [Literary portrait (origins, poetics, genre)]. L.: Nauka, 1985. 312 s.

5. Kovtun N.V. Obraz gorodskoj civilizacii v pozdnih rasskazah V.M. Shukshina: mimeticheskij i semanticheskij aspekty [The image of urban civilization in the later stories of V.M. Shukshin: mimetic and semantic aspects] // Vestnik Tomskogo gosudarstvennogo unstituta, No. 1 (17). 2012. S. 74-94).

6. Kovtun N.V. Priroda i religiya kak osnova zhiznennogo uklada v povesti V. Astaf'eva „Starodub" [Nature and religion as the basis of the way of life in V. Astafiev's story "Starodub"] // Vestn. TGU. Filologiya. 2009. No. 1 (5). S. 71-83.

7. Krylov V.N. Russkaya literaturnaya kritika. Problemy teorii, istorii i metodiki izucheniya [Russian literary criticism. Problems of theory, history and methods of study]. M.: FLINTA, 2016. 239 s.

\section{About the author}

Andreeva Elena Aleksandrovna - post-graduate student, Krasnoyarsk State Pedagogical University named after V.P. Astafiev; e-mail: andreeva.elena.krsk@gmail.com 